\title{
Language pattern of Yoruba-English teenage school-going bilinguals in southwest Nigeria: Impact on the English language and suggestions for language planning
}

\author{
Dare Owolabi
}

Department of English and Literary Studies

Ekiti State University, Ado Ekiti, Nigeria

\begin{abstract}
As in many parts of the world, bilingualism is a common speech phenonmenon in Southwest Nigeria as many who have had exposure to western education are exposed to both Yoruba and English at about the same time and in the same environment. While Yoruba is the Mother Tongue, the English language is both the nation's official as well as the second language and, by extention, the language common to many in this part of the country's geopolitical zone. As the official language of education, the English language now faces serious challenges as it competes, in so many domains, with Yoruba, the language of the immediate environment, thus impinging negatively on the effectiveness of the use of the English language. The study is both a survey and descriptive using a simple questionnaire for the survey. The findings show a shift from the indigenous language to English,but the preference for English does not translate to mastery of the language. Results from public examinations indicate that the contact between the two languages affects the effective use of the English, which is the nation's official language in schools. The study recommends, for the purpose of language planning, a tripartite lingustic model, with multilingualism at the base, for cultural matters, interpersonal communication in local trade and phatic communion; regional/geopolitical zone bilingualism in the middle of the pyramid, with the whole model peaking and coalescing at national monolingualism in a pyramidal form, with English retaining its prsent position at the peak of the pyramid.
\end{abstract}

Keywords: bilingualism; competence; language pattern; language contact; language conflict; language endangerment; language planning.

\section{Council for Innovative Research}

Peer Review Research Publishing System

Journal: Journal of Advances in Linguistics

\author{
Vol 1, No.1 \\ editor@cirworld.com \\ www.cirworld.com, member.cirworld.com
}




\section{Introduction}

Language is a human phenomenon that is central to every activity of man because there is no aspect of human existence that language does not play a vital role. Language is so important that it is a mark of the human race, and it distinguishes man from the lower primate. The natural linguistic state of man is monolingualism but Nunn (2005: 4) says "More than half the world's population is not monolingual" and Fromkin, et al (2007: 343) also say "Approximately half of the people in the world are native speakers of more than one language". This is so because the gregarious nature of human beings makes it possible to violate this natural monolingual state as they acquire more than one language one way or the other. For instance the demands of education make bilingualism a must, especially when the mother tongue, which is the language of interaction in the immediate environment, is different from that of instruction in school. In Southwest Nigeria for example, exposure to two different languages, in most cases at the same time, and in some cases, from infancy makes bilingualism part of their life. The National Policy on Education (NPE, 2003) recommends the language of the immediate environment for use as the language of instruction in the first two years in school, and English from the third year up to the university level. Although bilingualism is defined as "the ability to speak two languages fluently" (McLaughlin, 2006:403) or "Having an effective control of two native languages" (Matthews, 2005:38); that is "having competence, both grammatical and communicative in more than one language" (Finegan, 2004:573), Matthew has said the term now refers "Loosely or more generally, in some accounts, of people or communities that have two or more different languages, whether or not control is effectively equal and whether or not more than one is native" (p. 38). This has also been expressed earlier by Crystal (2003), implying that bilingual competence deals with less, rather than more of monolingual ability. He says:

Definitions of bilingualism reflect assumptions about the degree of proficiency

people must achieve before they qualify as bilingual (whether compaprable to a

monolingual native speaker, or something less than this, even to the extent of

minimal knowledge of a second language (p. 51).

Majority of the subjects for this study fall within the category of compound compound bilingualism, which involves the use of two languages interchangeably, with the simultaneous possession of both languages as they are spoken in the same domains, although without clear evidence of equal mastery of the two languages.

\section{The Problem}

Learning or acquiring a second language is not without its own attendant problems, especially when an acquired language and a target language are supposedly required in different domains within the same environment. English-Yoruba bilinguals in Southwest Nigeria present a case study on the effects of language contact in a multilingual nation. Adegbite (2009:75) has noted that: "Despite the high status accorded the English language in Nigeria, competent speakers of the language remain few (5-10\%). Records of poor performance and usage are given at all levels of education and strata of communication in the society". While the Yoruba language is picked up at home, being the language of the immediate environment, majority of our subjects pick up the English language at school. Most often, this latter language is used only in formal settings and so its use is limited. This notwithstanding, the language is required in the educational pursuit because the National Policy on Education (NPE, 2003) prescribes it. What this means is that this category of people is confronted with two languages; one used often in almost all domains, including the school, except in the classroom, the other made mandatory by the demands of government on the use of language in education. This category of people is, therefore, torn between two cultures represented by the two languages they are directly exposed to.

Although some of our subjects are exposed to English early in life, in some other domains, they are negligible compared to the entire population in this study. Because of the early exposure to Yoruba and later to English, or to both, but in competition, simultaneously, there is the usual problem expected in every language contact situation. Our interest here is this set of bilinguals' language pattern and how it impacts on effective use of language, especially the English language required in important domains other than the home. Adegbite (2009:91) captures this problem when he says: "Because many children are exposed to learn English without giving due regard to their mother tongue, the children end up failing to achieve mastery of either language". The critical nature of the effects of the contact between these two languages is borne out of the fact that languages in contact are always competing thus resulting in language conflict (Egbokhare, 2004).

\section{Theoretical Framework}

Chomsky's Language Acquisition Device (LAD) confers on a child the innate ability to acquire any language the child is exposed to. Jesperson (1922) also says a child with a language faculty naturally acquires any language no matter how stupid the child, whereas an adult learner of a second language after having acquired one, will always falter, no matter how intelligent. The critical age of language learning is put at under puberty after which it is difficult, if not impossible, to learn a new language effectively. Even with concerted efforts after this critical age, it is only the grammatical structures that can be learnt perfectly as the phonological aspects of a new language are not easy to master. Research findings have shown that age is a major constraint in phonology. For example, age of arrival, rather than length of stay in the US, has been found to be a major determinant of the extent to which a speaker would acquire near-native pronunciation (Lennon, 1993). Although there are still disputes on the critical period hypothesis, Carroll (2004:317) concludes that "young children generally learn L2 better than older children and adults, at least in the long run". Many of the subjects for this study, although fall within the critical age bracket, the frequent exposure to one of the two languages under study; that is the Yoruba language, which is their mother tongue, has made effective acquisition of the two languages difficult, with many of 
them not quite proficient in either (Adegbite, 2009). This appears to cotradict the innate theorists that the mind is capable of expressing anything, as opposed to the behaviourists' notion that linguistic cognition is borne out of the empiricists' view that the environment plays a major role in a child's linguistic development.

The dichotomy between innatism and behaviourism is better resolved by a synthesis of the two schools of thought rather than sacrifice one for the other. In the final analysis, it should be conceded to innatism the mind's infinite capability to express or understand what it is exposed to, thus equally acceding to the behaviourists' belief that the mind, if not exposed to the outside environment, will be limited in what it can express or understand as captured in the words of Georgr Bekerly Esse est percepi (To be is to be perceived). This has also been the position of Jean Piaget that the physical development of a child cannot be divorced from the child's intellectual or cognitive development, and this, too, largely depends on the interaction between inherent and innate capabilities and outward and environmental experiences.

\section{Research Objectives}

This study set out to:

i) identify the pattern of language use by Yoruba-English teenage school-going bilinguals in southwest, Nigeria;

ii) identify the effects of language contact on effective use of English by Yoruba-English teenage school-going bilinguals, being the official language and language of education in Nigeria.

\section{Research Questions}

With the above objectives in mind, the study answered the following research questions:

1. What is the pattern of language use among Yoruba-English teenage school-going bilinguals in southwest Nigeria?

2. What are the effects of language contact on effective use of English being the official language and language of education in Nigeria?

\section{Research Design and Methodology}

This study is a survey designed to identify the language pattern of Yoruba-English bilinguals in southwest Nigeria. The population therefore consisted of school-going teenagers (13-19 years) in this country's geopolitical zone. For the purpose of convenience and the constraints of time and money only two hundred and forty five samples from randomly selected four secondary schools in Ondo State were used for this study. Like every survey, this study investigated the current state of things through data collection and analysis from a small number of the entire population considered representative enough and generalising the results to the entire population. Two research questions in line with the earlier stated research objectives were answered, using a questionnaire prepared by the researcher and scrutinized by an expert in sociolinguistics. Usually, a survey research provides no basis for hypothesis testing due to lack of variables that can be manipulated; instead, answers are provided to research questions based on available data. Copies of the questionnaire were administered personally, and with the aid of two research assistants.

\section{Data presentation, analysis and discussion}

Data gathered were regrouped and then subjected to descriptive statistical analysis to answer the research questions. Being a survey using descriptive statistics, simple percentages and frequency counts were used and the results are as discussed in the following section. The table below shows respondents' answers to the items in the questionnaire.

\section{Data presentation}

Table 1: Respondents' answers to the items in the questionnaire
13
14
15
16
17
18
19

Respondents' Ages 55(22.45) 57(23.27) 56 (22.86) 53(21.63) 20(8.16) 03(1.23) 01(0.41)

\begin{tabular}{llccc} 
& \multicolumn{1}{l}{ Yoruba } & English & Russian \\
Language first exposed to & $215(87.76)$ & $29(11.84)$ & $1(0.41)$ \\
& $3-6 \quad 7-12$ & $13-19$ & No Response \\
Age of exposure to Yoruba & $200(81.63)$ & $30(12.25)$ & $0(0)$ & $15(6.12)$ \\
Age of exposure to English & 236(96.33) & $0(0)$ & $0(0)$ & $09(3.67)$
\end{tabular}

$\begin{array}{lccccc} & \text { Home } & \text { School } & \text { Environment } & \text { Church } & \text { Others } \\ \text { Place of first exposure to Yoruba } & 168(68.57) & 25(10.20) & 46(18.78) & 6(2.45) & 0(0) \\ \text { Place of first exposure to English } & 147(60.0) & 73(29.80) & 25(10.20) & 0(0) & 1(0.41)\end{array}$

$\begin{array}{lccccc}\text { Language used: } & \text { English } & \text { Yoruba } & \text { Others } & \text { English/Yoruba } & \text { No Response } \\ \text { At home } & 70(28.57) & 110(44.90) & 12(4.90) & 50(20.41) & 3(1.22)\end{array}$




\begin{tabular}{|c|c|c|c|c|c|}
\hline At school & 243(99.18) & $0(0)$ & $0(0)$ & $0(0)$ & $2(0.82)$ \\
\hline At worship place & $137(55.92)$ & $41(16.73)$ & $0(0)$ & $63(25.71)$ & $4(1.63)$ \\
\hline With strangers & 170(69.39) & $30(12.24)$ & $0(0)$ & 40(16.33) & $5(2.04)$ \\
\hline With friends & $118(48.16)$ & $53(21.63)$ & $0(0)$ & $70(28.57)$ & $4(1.63)$ \\
\hline With parents & $43(17.55)$ & $112(45.71$ & $10(4.08)$ & 75(30.61) & $5(2.04)$ \\
\hline With siblings & $75(30.61)$ & $85(34.89)$ & $5(20.04)$ & $70(28.57)$ & $10(4.08)$ \\
\hline & & English & Yoruba & glish/Yoruba & a Russian/English \\
\hline Language more cc & nfortable with: & $140(57.14)$ & ) $62(25.31)$ & $2(17.14)$ & $1(0.41)$ \\
\hline Language now pre & erred: & $191(77.96$ & 6) $35(14.29)$ & $16(6.53)$ & $1(0.41)$ \\
\hline Frequency of Eng & h use with: & Often & Rarely & Never & No Response \\
\hline Parents & & $92(37.55)$ & $145(59.18)$ & $1(0.41)$ & $7(2.88)$ \\
\hline Siblings & & $180(73.47)$ & $62(25.31)$ & $0(0)$ & $3(1.22)$ \\
\hline Strangers & & $140(57.14)$ & $85(34.69)$ & $0(0)$ & $20(8.16)$ \\
\hline Frequency of Yorl & a use with: & Often & Rarely & Never & No response \\
\hline Parents & & $135(55.10)$ & $55(22.49)$ & $16(6.53)$ & $39(15.92)$ \\
\hline Siblings & & $95(38.78)$ & $115(46.94)$ & $16(6.53)$ & $19(7.76)$ \\
\hline Strangers & & $45(18.38)$ & 155(63.27) & $41(16.74)$ & $4(1.63)$ \\
\hline Friends & & $105(42.86)$ & $105(42.86)$ & 16(6.53) & $19(7.76)$ \\
\hline Communication pr & ficiency in: & Very well & Fairly well & lot at all & No Response \\
\hline English & i) Oral & 196(80.0) & $44(17.96)$ & $0(0)$ & $5(2.04)$ \\
\hline & ii) Written & $154(62.86)$ & $33(13.47)$ & $0(0)$ & $58(23.67)$ \\
\hline Yoruba & i) Oral & 137(55.92) & 73(29.80) & $24(9.80)$ & $7(2.88)$ \\
\hline & ii) Written & $56(22.86)$ & $137(55.92)$ & $26(10.61)$ & $26(10.61)$ \\
\hline Comprehension o & dioms/proverb & bs in: Very we & ll Fairly well $\mathrm{N}$ & Not at all $N$ & No Response \\
\hline English & & $125(51$. & .02) 105(42.86) & $0(0)$ & $15(6.12)$ \\
\hline Yoruba & & $15(6.12$ & $85(34.69)$ & $15(6.12)$ & $130(53.0)$ \\
\hline Penalty for Englis & use at home & & $5(2.04)$ & & $40(97.96)$ \\
\hline Penalty for Yorubs & use at school & & 235(95.92) & & $10(4.08)$ \\
\hline Frown at Yoruba & e at home? & & $30(12.24)$ & & $215(87.76)$ \\
\hline
\end{tabular}

All the respondents were between 13 and 19 years of age and were all school-going at the time of the research. 215 (87.76) were first exposed to Yoruba, while 29 (11.84) were first exposed to English and 1 (0.41) was exposed to Russian first. They were introduced to the two languages at various ages. For the purpose of convenience, the ages were grouped 3-6, 7-12 and 13-19. 200 (81.63) of the respondents were introduced to Yoruba between 3 and 6years, 30 (12.25) between 7 and12 years and nobody was introduced to Yoruba at an age later than that while 15 (6.12) did not respond at all. 236 (96.33) of the respondents said they were first introduced to English between 3 and 6 years and nobody was introduced to English at an age later than that, but 9 (3.67) did not respond to the question. It is interesting to note that while some were introduced to Yoruba between the ages of 7 and 12, no one was introduced to English at that age range, but earlier. The implication of this is that many of the respondents had English introduced to them at infancy. Yoruba was introduced to $25(10.20)$ at school, $46(18.78)$ in the environment and 6 (2.45) in the church. On the other hand, English was introduced to $73(29.80)$ at school, $25(10.20)$ had it introduced to them in the environment, while none had English introduced to him/her in the church, but one simply said English was introduced to him in Nigeria, and that is the one born of a Russian mother in Russia. What this translates to is that nearly all the respondents had English introduced to them in various environments where the Yoruba language is also in use, thus making it possible for the two languages to compete favorably.

The home was the place of first introduction to both languages with 168 (68.57) and 147 (60.0) for Yoruba and English respectively for many of the respondents. Other places of first exposure to the languages include school 25 
(10.20) and 73 (29.80) environment 46 (18.71) and 25 (10.20) and church 6 (2.45) and 0 (0) for Yoruba and English respectively.

\section{Research question 1: What is the pattern of language use among Yoruba-English teenage school-going bilinguals in southwest Nigeria?}

From the findings in this study, it is obvious that this category of bilinguals is shifting from the mother tongue, which is Yoruba to English with majority of them now claiming to be more comfortable in English (140 (55.51)) and 62 (24.90) more comfortable in both Yoruba and English thus upping the level of comfort in English as against 42 (16.73) who are comfortable in Yoruba and 62(24.90) in Yoruba and English. One respondent born in Russia, however, shows more comfort in Russian. In almost all domains except the home with 70 (28.57), and with parents 43 (17.55) and siblings 75 (30.61), English is the language used, as indicated in the responses: at school 243 (99.18), worship place 137 (55.92), with strangers 170 (69.39) and with friends 118 (48.16). With a combination of Yoruba and English in some other domains such as home 50 (20.41), worship place 63 (25.71) with strangers 40 (16.33), friends 70 (28.57), parents 75 (30.61) and siblings 70 (28.57) the odds seem to be more against Yoruba which is only used at home 110 (44.90) at worship place 41 (16.73) and with parents and siblings 112 (45.71) and 85 (34.89) respectively. In fact, all the respondents claimed Yoruba is not used in school at all. This claim appears bogus because, in a recent study, Oyetade (2007:178) reports that:

\section{...in communication with classmates and pupils junior or senior}

to themselves, more than $50 \%$ of the respondents in all cases claim to

use only English. Yoruba ranks second at school, with more than 25\%

claiming to use it alone in talking with classmates and pupils senior or

junior to themselves, but $62 \%$ claiming to use Yoruba alone when

talking generally during break.

It is clear that English is the preferred language with 140 (55.51) now more comfortable in it as against 62 (24.90) in Yoruba and when those comfortable in both Yoruba and English 42 (16.73) are added, English has an edge. This is considering the fact that those in this latter category of English and Yoruba will most likely dump Yoruba for English at the slightest opportunity, especially in other domains different from the home and with parents and siblings. From these findings, it is obvious that Yoruba-English bilinguals in the southwest Nigeria are tending towards a more frequent use of English than Yoruba in more domains. This tendency towards English does not, however, translate to effectiveness when it comes to the use of standard Englsh, and so the self-report of being comfortable in English may be a bogus claim after all. Although they may not have native-speaker competence, they are nonetheless bilinguals (cf. Crystal, 2003). What they can possibly boast of, in their claim of being comfortable in English, is the distinction that has been made between Basic Interpersonal Communication Skills (BICS), from Cognitive/Academic Language Proficiency (CALP) (cf. Cummins, 1979; Baker (2000 \& 2002).

Research Question 2: What are the effects of language contact on effective use of English being the official language and language of education in Nigeria?

Language contact has direct effect on the communicative competence of the respondents. This is not unexpected. 196 (80.0) of the respondents believe they are very competent in spoken English, 154 (62.86) in written English, whereas 137 (55.92) believe they are very competent in spoken Yoruba and only 56 (22.86) believe they are very competent in written Yoruba. The wide disparity between competence in written English and written Yoruba may be due to the fact that English is not only taught as a school subject appearing five times on the school time table, the languge is also used in all the school subjects, while Yoruba is only taught as a school subject, appearing three times on the school time table. Besides, a pass in Yoruba hardly gives the students any advantage, except those who may wish to study the language at a higher level, and such students are always very few. The high response of very competent in spoken Yoruba 137 (55.92) may be attributed to the use of the language often with parents 135 (55.10) as against the frequent use of English 92 (37.55) and also the frequent use of the language with friends 105 (42.86) (cf Oyetade, 2007). The very competent use of spoken Yoruba does not translate to same in written Yoruba and this may be due to the fact that oracy is not really a mark of literacy. Besides, Yoruba movies are now very common as home videos to which many may be exposed. Other responses showed that the respondents were fairly well competent in spoken English 44 (17.96); written English 33 (13.47) and spoken Yoruba 73 (29.80); written Yoruba 137 (55.92). It is interesting to observe that none lack competence in both spoken and written English, whereas 24 (9.80) and 26 (10.61) responded to total lack of competence in spoken and written Yoruba respectively. Others who did not respond to the questions include: 5 (2.04) and 58 (23.67) respectively for spoken and written English and 7 (2.88) and 26 (10.61 for spoken and written Yoruba respectively.

On the comprehension of idioms and proverbs in the two languages, 125 (51.02) of the respondents believe they very well understand; 105 (42.86) fairly well understand $0(0)$ for not at all and 15 (6.12) did not respond at all for English. In the case of Yoruba, only 15 (6.12) believe they very well understand idioms and proverbs; 85 (34.69) believe they fairly well understand; 15 (6.12) not at all and 130 (53.06) failed to respond to the question. From these responses the effects of the two languages coming into contact are as discussed below.

\section{Effects of Yoruba-English contact on teenage school-going children in southwest Nigeria}

When languages come in contact, it is not without some natural consequences, which may be favorable to one and adverse to the other. Such effects also impinge on the people involved in the contact. The findings in this paper revealed 
the first direct victim or beneficiary of languages coming into contact is the individual. The individual experiences a conflict of cultures as he is torn between two cultures represented by the two languages in contact. This culture clash may lead to split personality which has been identified as a major cause of disorientation among youths who fall into the category of the subjects in our study. The inevitable interference in the contact between the two languages may make this category of bilinguals lack proficiency in the two languages that they cannot be said to be proficient in either (Adegbite, 2009). They are, nonetheless, compound bilinguals because they learn the two languages in the same setting, acquiring "one notion with two verbal expressions" (Rosania Maria, 1990).

Apart from being studied as a subject on the school time table, the Yoruba language is prohibited from use in the school system. In some cases its use, within the school hours, even for non-educational purposes, attracts sanctions (Fakuade, 2004), and as evident from the findings 235 (95.92) indicated they are penalized for the use of Yoruba at school, whereas no such penalty for the use of English at home 240 (97.96). this kind of situation tends to promote substractive bilingualism, which is not beneficial to the bilingual. Yoruba is the language of the immediate environment and so way of coming up and it is constantly in use, although unofficially, even within the school system (Oyetade, 2007). The use of Yoruba is also encouraged as 215 (87.76) indicated it is not frowned at by parents and siblings. The natural consequence of this is the direct interference at the individual level which may negatively affect the use of English needed for other school subjects, thereby affecting academic performance of those in this age category. Another direct effect of this is the possible decline in the standard of education and its attendant effects on national development. It is reported that majority of the students that sit for the Senior School Certificate Examination (SSCE) record very poor results in the English language which tends to negate the claim of the respondents that they are proficient or comfortable in the language. The table below shows candidates'performance in public examinations over a period of time.

Table 2: Summary of Nigerian students performance in English in selected May/June SSCE

\begin{tabular}{|l|l|l|l|l|l|l|}
\hline YEAR & $\begin{array}{l}\text { NO } \\
\text { CANDIDATES }\end{array}$ & $\begin{array}{l}\text { GRADES 1- } \\
6\end{array}$ & $\begin{array}{l}\text { GRADES } \\
\& 8\end{array}$ & $\begin{array}{l}\text { TOTAL } \\
\text { GRADES 1- } \\
8\end{array}$ & GRADE F9 & ABSENT \\
\hline 1995 & 464,270 & $\begin{array}{l}57,568 \\
12.4 \%\end{array}$ & $\begin{array}{l}128,480 \\
27.7 \%\end{array}$ & $\begin{array}{l}186,068 \\
40.1 \%\end{array}$ & $\begin{array}{l}278, \\
59.9 \%\end{array}$ & 202 \\
\hline 1998 & 636,777 & $\begin{array}{l}53,990 \\
8.5 \%\end{array}$ & $\begin{array}{l}136,873 \\
21.5 \%\end{array}$ & $\begin{array}{l}190,70103 \\
30.00 \%\end{array}$ & $\begin{array}{l}417,312 \\
65.5 \%\end{array}$ & $3,8490.6 \%$ \\
\hline 1999 & 752,233 & $\begin{array}{l}73,531 \\
9.7 \%\end{array}$ & $\begin{array}{l}171,098 \\
22.6 \%\end{array}$ & $\begin{array}{l}244,629 \\
32.3 \%\end{array}$ & $\begin{array}{l}471,593 \\
64.9 \%\end{array}$ & $3,8270.5 \%$ \\
\hline \multirow{2}{*}{2000} & 784,129 & $\begin{array}{l}84,932 \\
9.8 \%\end{array}$ & $\begin{array}{l}172,158 \\
21.4 \%\end{array}$ & $\begin{array}{l}257,090 \\
31.20 \%\end{array}$ & $\begin{array}{l}523,117 \\
65.9 \%\end{array}$ & $3,9220.6 \%$ \\
\hline
\end{tabular}

Source: West Africa Examination Council

Figures in the above table negate the claim by some of the respondents, who are in the same age bracket with those who sat for these examinations, that they are comfortable in English, considering the fact that grades 1-6 are the acceptable level of performance for further education in Nigeria. In more recent year, 2006, only $11.56 \%$ of the 423,518 for the November/December SSCE by the same West Africa Examinations Council conducted public examination passed with credits in the two core subjects: (English and Mathematics) and three others (Belo-Osagie, 2006). There is no evidence in recent years to dispute this 2006 statistics, which is consistent with the ones in the table above, as failure rate in English and the other core subject has not reduced.

Much as this category of respondents seems to desire proficiency in the English language to enable them function well in the society, the pressure from the immediate environment makes it impossible for them to completely abandon the Yoruba language. The implication is that outside the classroom, there will be code-switching and code-mixing, as speakers shift from English to Yoruba and vice versa (Oyetade, 2007). The practice of code-switching now commonly observable among people in this age group may also diminish the effective performance in English needed for academic purposes, to the extent that they may not be able to reach their optimal level in the other school subjects. This category of bilinguals now fall under an emerging type of bilingualism called 'limited' bilinguals (Baker, 2001) or what Dada (2006) regards as 'semi-linguals'.

\section{Bilingualism and language endangerment}

Some of the respondents are within the critical age of language learning and since they are exposed to the two languages almost at the same time, and they use the languages constantly, neither of the two languages appears threatened nor in serious danger of extinction. Although there is serious preference for English for obvious reasons, conflict is obvious as it 
is expected of languages in contact (Egbokhare, 2004). This conflict is seriously affecting the effective use of English, which is the de jure official linguistic code of the nation.

Bilingualism is more or less the rule and not the exception in most parts of the world, especially in Africa and Asia (Nun, 2005; Fromkin, Rodman \& Hyams, 2007). The degree of competency, however, varies depending on the time and place of contact with the two languages. The findings here have shown that 236 (96.33) came in contact with the English language between 3 and 6 years of age and 200 (81.63) came in contact with Yoruba within the same age range; in both cases at home and school. The findings also showed that Yoruba is used more at home 110 (44.90) than English 70 (28.57); more with parents 112 (45.71) than 43 (17.55) for English, and also more with siblings 85 (34.89) than 75 (30.61) for English (cf. Oyetade, 2007). This shows that their contact with English is mainly at school 243 (99.18) as they revert to the use of Yoruba as soon as they leave the classroom. This kind of additive and subtractive bilingualism, which favors the development and maintenance of maternal language and at the same time, permits the learning and use of a second language (Fakuade, Gambo \& Bashir, 2003) is in the interest of the continued existence of the Yoruba language, but detrimental to the effective mastery of the English language. According to Microsoft Encyclopedia (2002), there is a resurgence of interest and pride in indigenous African languages in many parts of the continent, and despite the increase in contact between Africa and the West in the past 50 years, most African languages 'show no sign of dying out.' This is without prejudice to the linguistic hegemony, which the English language still enjoys, as Nation (2003: 4) has noted that " In some countries, English and L1 are in competition with each other and the use of English increases at the expense of the L1."

Language contact is a natural consequence of societal demands on this category of people. What this therefore means is that those in this age range use the English language for educational and official purposes as well as outside the school system for purposes other than education, considering especially the multilingual nature of Nigeria. The Yoruba language is used more outside the school system, especially at home with parents and siblings and a combination of the two for sundry purposes. So, language contact takes place everywhere, and from time to time.

\section{Suggestions for language planning}

As noted by Adegbite (2009: 76): "In a multilingual nation like Nigeria, an uncordinated linguistic diversity may result in the creation of many problems like educational underdevelopment, ethno-linguistic agitation, breakdown of information and communication gap between the government and the people". Language planning therefore calls for careful considerations.

As no major African state is conterminous with monolingual entity, a monolingual Nigeria is neither feasible now nor in the distant future, for reasons that are well known. With the current multilingual nature of Nigeria, which has a guaranteed existence for a long time, "the idea of linguistic oneness (unilingualism) was seen as a delicate matter, and a potential source of ethnic conflict, that needed to give way to plurilingualism" (Adegbite, 2004: 20). The idea of an indigenous code as a national language might have been fashionable in Nigeria up to the early 1980's, the current state of affairs in the nation does not seem to favour such a venture, and it is not likely to be in the minds of those that matter. Any attempt, except as a linguistic or an academic exercise, to prescribe a single indigenous linguistic code as a national language will most likely shatter the unity which the English language thinly sustains currently. To that extent, a tripartite pyramidal linguistic model is recommended to language planners. This model will encourage additive and sequential bilingualism and attainment of both Basic Interpersonal Communication Skills (BICS) and Cognitive Academic Language Proficiency (CALP) as enunciated by Cummins (1981).

\section{Fig. 1: Tripartite Pyramidal Linguistic Model}

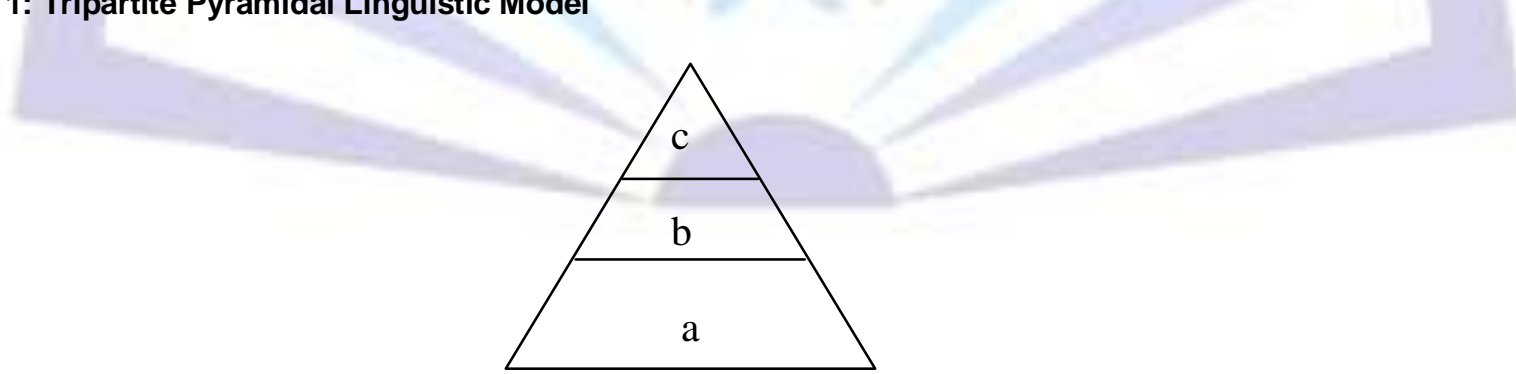

a. At the base of the pyramid, multilingualism is promoted for cultural matters, interpersonal communications in trade, phatic communion, etc. this will give due attention to people's language beliefs, cultures and practices in the process of language planning (Mustapha, 2003: 54).

b. In the middle, bilingualism is encouraged for national and educational matters.

c. At the peak, monolingualism is enforced for international communication.

The above scenario recognizes Adegbite's (2004:19) position, when he says: "Although, English is incontestably the language of nationhood, it need not dominate the state (even in multi-ethnic states) and local government levels...". In a similar vein, Adedimeji (2006:42), while advocating Global English (GE) as standard, still makes a case for the existence of Nigeria's indigenous languages. He says: "...Nigerian languages will be serving as the medium of intra-ethnic/proximate communication, NE for proximate/intermediate communication and GE for ultimate/international communication...". 
Oyetade (2011), has also noted the preponderance of English language use in high domains and the prevalence of indigenous languages in the low (or primary) domains.

The real need for English is usually limited, and it is not evident at the base of the pyramid, but becomes more evident as from the midpoint in its various regional domesticated varieties. This coalesces, finally, at the peak, where standard Nigerian English will be norm. This is an option for language planners, which, if well pursued will lead to lingustic sanity in Nigeria's multilingual setting. The various proposals to evolve a national language have failed, and may continue to fail, if we attempt to plan for language in a multilingual nation such as Nigeria, without putting the English language into consideration, because from statistics, it is more preferred by teenage school-going children, the future generation. Banjo and Unoh (1980: 59) seem to have taken this position a long time ago when they say "It is not very rational to reject English chauvinistically just because it is the language of a former colonial power, if it had a certain place and certain resources invested in it in the country concerned." Jowitt (1991: 22) has observed the fact that "English continues to perform many of the functions of a national language as well as those of an official language, and probably would continue for a long time to do so even if some other language were imposed on the country by Government policy...". Adesanoye (1994) also says it is unwise to rashly abandon the English language, until the nation can do without it. Banjo (1995: 187), in like manner believes:

\section{...if Nigeria is to make a distinctive contribution to human civilization, \\ it will have to be a result of the symbiotic relationship between English and the \\ indigenous languages, a pooling of the resources of all the languages without \\ foreclosing the contributions that any of them can make.}

This concept has been re-echoed in recent times, when Nunn (2005: 6) says: "A colonial past may provide hostility towards the language of the former colonialists, but pragmatism often prevails, with English being the most useful tool as a kind of lingua franca."As a global lingua franca, the English language has become part of every nation's linguistic family that cannot be ostracised when planning for language. This position will remain with us for a long time to come because "...English is the language of nationism (or inter-ethnic relations) in Nigeria. No other single indigenous language qualifies to perform this role" (Adegbite, 2004:19). In a more recent time, Adamo (2012: 51) says: "In the postcolonial era, English remains the language through which the country carries out its international transactions and through which the citizens access scientific and technological information." This position has been affirmed by Mustapha (2013:55). According to him:

$$
\begin{aligned}
& \text {..when due consideration is given to the demand for interaction with } \\
& \text { the English-speaking world, and speakers of English as their lingua } \\
& \text { franca (ELF), the opportunities that English as a world/international } \\
& \text { language of science and technology and advancement affords, one might } \\
& \text { come to a justifiable position on the place the English language should } \\
& \text { occupy in the language policy of any nation in our contemporary world. }
\end{aligned}
$$

This position far outweighs the patriots' rejection of the continued dominance of the English language, which they see as a perpetuation of colonialism that underdevelops our linguistic heritage and depletes our cultural values.

\section{Conclusion}

Several reasons account for language contact and foster bilingualism, such as "migrations of various kinds (economic, educational, political and religious), nationalism and federalism, education and culture, trade and commerce, intermarriage, etc" (Brenzinger, 2000). The most relevant reason for bilingualism for the subjects under study is education; although the language is also needful in other domains beyond the school system as it is the nation's official language as well as the language of wider communication. Although school-going teenagers in southwest Nigeria may be said to have bilingual first language or bilingual language acquisitions based on the age of exposure to both Yoruba and English, between 3 and 6 years of age (Carroll, 2004 and Fromkin, et al, 2007) at home and in the school, the two languages are constantly in conflict. Neither, however, appears to pose any threat of extinction to the other, notwithstanding that English is better preferred for reasons already identified in this study. In fact, it is the English language that is now at risk of being bastardised, notwithstanding the fear of Yoruba language going into extinction as expressed by some Yoruba patriots (Fabunmi \& Salawu, 2005; Akinyemi, (2009). Akinyemi says it has got to a stage where parents prohibit the use of the language as a medium of expression at home, regretting that although the Yoruba are the only tribe with a unified language in Nigeria, it is the one language despised by its owners. This appears to be a personal observation predicated on pure patriotism, rather than any empirical evidence, which this work has disproved. Some of the reasons given for the use of Yoruba by the respondents included, but not restricted to, love for the language, comprehension by all, fun, patriotism, better self-expression and to 'castigate the English language'. Some of these reasons agree with Bello (2001) quoting Bamgbose (2001) that it is still possible to be proud of self by identifying with a nationality which the native tongue powerfully symbolizes, and at the same time take maximum benefits that proficiency in English confers. These reasons also tally with the outcome of Bamisaye's (2006) study on language choice among bilinguals, where it was reported that $70 \%$ of the respondents prefer the mother tongue for various reasons including many of the reasons also identified in this study. Besides, the possibility of Yoruba dying out is very remote, if the reasons for language death such as death of all its speakers and complete language shift, where the speakers abandon the language for a more prestigious or a more useful 
one (Millar, 2007) are anything to go by. Neither of these two causes appears to threaten the existence of the Yoruba language for now or even in the future. In a pilot study, Akinjobi (2004) reports that "72\% of the subjects speak only Yoruba, $14 \%$ speak Yoruba and English and one of the three major languages and $14 \%$ also speak Yoruba, English and one or two other Nigerian language(s) apart from Hausa or Igbo language". In sum, all the subjects speak Yoruba. In Wurn (2003), cited by Igboanusi (2004), on five levels of language endangerment, Yoruba does not seem to be faced with any of those factors. Not only this, in Ohiri-Anichie's (1997) study, also cited by Igboanusi (2004), only 2\% of Junior Secondary School (JSS) students did not speak the local language (Yoruba) in Lagos State which is seen as a metropolitan city. If it is so in Lagos, it might be less in other Yoruba-speaking towns and villages. Lamenting the parlous state of lgbo, recognized as one of the major languages in Nigeria, Igboanusi (2004:6) says "although the dominance of English in Nigeria is affecting other Nigerian languages-both major and minor, it has affected Igbo more than the other two major languages, i.e. Hausa and Yoruba." Lawal (2006), citing Awonusi (2004), classifies Yoruba among the 'decamillionaire' languages, with at least, 10 million people speaking the language, just as Oyetade's (2007) study on the predatory nature of Yoruba language in the southwest also indicates the language shows no sign of dying out. According to him: "...Yoruba has a flourishing literary tradition including novels, drama, poetry, pedagogical materials, etc, as well as newspapers, magazines, and comics. A new dimension in the development of Yoruba is an upsurge in Yoruba films" (p.171). In the same study, Oyetade reports that $62 \%$ of the respondents claim the sole use of Yoruba when discussing generally at break time. This is a faily large number, and according to Igboanusi (2004: 4): "the larger the size of users of a language, the better its chances of survival." Also in a recent study, Dada (2012) reports that over 38\% of youths under 20 years of age still use the Yoruba language regularly. This number does not include those who use it irregularly, which is likely to be higher, going by the report of other studie. Ogunsiji (2013: 136) believes "...the Yoruba language will continue in its roles". This is an indication that the two languages will continue to exist side by side, for a long time to come, and the continued existence of the two languages will no doubt affect the standard of English as an international language. The language is now being affected by the contact as Dada (2012: 68) has noted that "linguistic interference or negative transfer of the forms and meanings of structure of the native language and culture to the target language is a major obstacle to the mastery of the English language". The English language is now coloured by local circumstances, in a phenonmenon now called domestication, leading to a fast emerging Nigerian English, with all its peculiarities as a variety of world Englishes.

\section{References}

Adamo, G. E. (2012). Linguistic interplay between Yoruba and English. English Today. $110,28(2), 51-53$.

Adedimeji, M. A. (2006). The phenomenology of English in Nigeria and the challenges of globalization. In Adegbite W. and Olajide, B. (eds). Reinventing the English Language in the Context of Globalization and Decolonization. Lagos: Olivetree Publishing Venture.

Adegbite, W. (2004). Bilingualism-biculturalism and the utilization of African languages for the development of African nations. In Oyeleye, L. (ed.). Language and Discourse in Society. Ibadan: Hope Publications.

(2009). Psycholinguistics of English language in Nigeria. Ibadan: Kraft

Books Limited

Akinjobi, A. (2004). Language chauvinism and the prospect of an indigenous national

language in Nigeria. In Oyeleye, L. (ed.), Language and Discourse in Society.

Ibadan: Hope Publications.

Akinyemi, A. (2009). The position of the Yoruba race among other races/tribes in

Nigeria. Nigerian Compass, Wednesday, June 10, 2009. p. 30.

Ayodele, S. O., Oyeleye, A. L, Yakubu, S. O. and Ajayi, D. A. (1990). General English:

A Course for the tertiary levels. Ibadan: paperback Publishers Limited.

Baker, C. (2000). The Care and Education of Young Bilinguals. Clevedon: Multilingual Press.

(2002). Bilingual education. In R. Kaplan. (Ed.), The Oxford Handbook of Applied Linguistics. Oxford: Oxford University Press.

Banjo, L. A. \& Unoh, S. O. (1980). Effective use of English. Lagos: Thomas Nelson

(Nigeria) Ltd.

Banjo, A. (1995). On language use and modernity in Nigeria. In Owolabi, K. (ed). 
Language in Nigeria: Essays in honour of Ayo Bamgbose. Ibadan: Group Publishers.

Bello, O. R. (2001). Discovering the link between language and society. Humanities Review Journal. 1 (2), 60-69.

Brenzinger, M. (2000). Language contact and language displacement. In Coulmas, F. (Ed.). The Handbook of Sociolinguistics. Oxford: Blackwell.

Carroll, D. W. (2004). Psychology of Language (4 ${ }^{\text {th }}$ Edition). Australia, Canada: Thomson Wadsworth.

Cummins, J. (1979). Cognitive/academic language proficiency, linguistic interdependence, the optimum age question and some other matters. Working Papers on Bilingualism, 19, 121-129.

(1981). Bilingualism and Minority Language Children. Ontario: Ontario Institute for Studies in Education.

Crystal, D. (2003). A Dictionary of Linguistics and Phonetics (5th edn). Oxford: Basil Blackwell.

Dada, S. A. (2012). Language policies and planning in Nigeria: Issues and perspectives. In Kuupole, D. D., Bariki, I. \& Yenna, R. (Eds.) (2012). Cross-currents in Language, Literature \& Translation. Porto-Novo: CUREF/IESSAF \& ESAF

Egbokhare, F. (2004). Language and politics in Nigeria. In Owolabi, K. and Dasylva, A. (Eds.). Forms and Functions of English and Indigenous Languages in Nigeria: A Festschrift in Honor of Ayo Banjo. Ibadan: Group Publishers.

Fabunmi, F. A. \& Salawu, A. S. (2005). Is Yoruba an endangered language? Nordic Journal of African Studies. 14 (3), 391-408.

Fakuade, G., Gambo, M., Bashir, A. (2003). Language shift from mother tongues towards Fulfulde in Adamawa State, Nigeria: Causes and consequences. Anthropological Linguistics 45 (3) 296-315.

Fakuade, G. (2004). Linguistic Genocide in Multilingual Nations: The Nigeria Experience. Inaugural Lecture at the Federal University of Technology, Yola, $14^{\text {th }}$ December, 2004.

Federal Republic of Nigeria (1981). National Policy on Education. Lagos: Government Press.

Finegan, E. (2004). Language: Its structure and usage (4th edn). Australia:Thomson Wadsworth.

Fromkin, V., Rodman, R. and Hyams, N. (2007). An Introduction to Language. Australia, Brazil: Thomson Wadsworth.

Igboanusi, H. (2004). Is Igbo an endangered language? Paper presented at the 24th West African languages Congress, University of Ibadan, August 1-6.

Jesperson, O. (1922). Language: Its Nature, Development, and Origin. London: Allen and Unwin.

Jowitt, D. (1991). Nigerian English Usage. Ikeja: Longman Nigeria Limited.

Lawal, A. (2006). Globalization and the and the repercussions of Englishization in Nigerian education. In Adegbite W and Olajide, B. (eds). Reinventing the English Language in the Context of Globalization and Decolonization. Lagos: Olivetree 
Publishing Venture.

Lennon, P. (1993). The advanced learner: Affective, social and motivational factors.

Language Learning Journal 8.

Matthews, P. H. (2005). The Concise Oxford Dictionary of Linguistics. Oxford: Oxford

University Press.

McLaughlin, S. (2006). Introduction to Language Development (2nd edn). Australia:

Thomson Delmar Learning.

Microsoft Encarta (2002). African languages.

Millar, R. M. (2007 revised). Trask's Historical Linguistics (2 ${ }^{\text {nd }}$ Edition). London:

Hodder Arnold.

Mustapha, A.S. (2013). Revisiting language policy in Nigeria. In Adegbite, W., Ogunsiji,

A. and Taiwo, $\mathrm{O}$ (ed.). Linguistics and the Glocalisation for Sustainable

Development (A Festschrift in honour of Prof. Kola Owolabi. Ibadan: Universal Akada Nigeria Limited.

Nation, P. (2003). The role of the first language in foreign language learning. Asian EFL Journal: English Language and Research Articles. 5 (2) 1-5.

Nunn, R. (2005). Competence and teaching English as an international language. Asian EFL Journal: English Language and Research Articles. 7 (3) 1-12.

Ogunsiji, Y. (2013). The nexus of Yoruba and English in a bilingual society. In Adegbite, W., Ogunsiji, A. and Taiwo, $O$ (ed.). Linguistics and the Glocalisation for

Sustainable Development (A Festschrift in honour of Prof. Kola Owolabi. Ibadan:

Universal Akada Nigeria Limited.

Oyetade, S. O. (2007). Language endangerment in Nigeria: Perspectives on Akoko languages of the southwest. International Journal of the Sociology of Language, 184, 169-184.

Oyetade, S. O. (2001). Attitude to foreign languages and indigenous language use in

Nigeria. In Igboanusi, H. (ed.). Language Attitude and Language Conflict in West

Africa. Ibadan: Enicrownfit Publishers.

Rosaria Maria, D. (1990). Three types of bilingualism. Paper presented at the Annual of the International Association of Teachers of English as a Foreign Language (24th Dublin, Ireland, March 27-30. Available at http://www.eric.ed.gov/contentdelivery/serviet/ERICService?accno=ED32154

Wallwork, J. K. (1978). Language and People. London: Heineman Educational Books. 